\title{
Metallomics
}

Cite this: Metallomics, 2013, 5, 214

Received 19th August 2012, Accepted 17th January 2013 DOI: $10.1039 / c 3 m t 20166 j$ www.rsc.org/metallomics

\section{Unexpected impact of the number of glutamine residues on metal complex stability $\dagger$}

\author{
Nadine M. Chiera, ${ }^{a}$ Magdalena Rowinska-Zyrek, ${ }^{\text {tb }}$ Robert Wieczorek, ${ }^{b}$ \\ Remo Guerrini, ${ }^{a}$ Danuta Witkowska, ${ }^{b}$ Maurizio Remelli*a and Henryk Kozlowski ${ }^{\mathrm{b}}$
}

\begin{abstract}
The emerging question which this study aims to answer is: what impact do glutamines have on the stability of metal-peptide complexes? We focused our attention on the N-terminal domain of Hpn and Hpn-like proteins from Helicobacter pylori. $\mathrm{Cu}^{2+}$ and $\mathrm{Ni}^{2+}$ complexes of the model peptides MAHHE$\mathrm{NH}_{2}$, MAHHEEQ- $\mathrm{NH}_{2}$, MAHHEQQ- $\mathrm{NH}_{2}$ and MAHHEQQHQA- $\mathrm{NH}_{2}$ were studied by means of different thermodynamic and spectroscopic techniques, as well as through molecular modelling computation. Experimental results, in very good agreement with theoretical findings, lead to the not obvious conclusion that the stability of metal complexes distinctly increases with the number of glutamine residues present in the peptide, although glutamine side-chains do not directly take part in coordination. This peculiar finding allows one to look at polyglutamine sequences, not only the ones present in some bacterial chaperones but also those involved in several neurodegenerative diseases, from a new perspective.
\end{abstract}

\section{Introduction}

Hpn and Hpn-like are two of Helicobacter pylori's cytoplasmic proteins involved in the homeostasis of nickel. They are important cofactors for urease (a di-nickel enzyme essential for the colonization of the bacterium) and hydrogenase (Ni-Fe enzyme responsible for energy production). ${ }^{1,2}$ A proper nickel homeostasis is crucial for this gastrointestinal pathogen involved in gastritis, duodenal ulcers, and formation of some kinds of gastric tumors. ${ }^{3,4}$ On the other hand, an excess of nickel ions is potentially toxic and can cause cellular damage. Recent studies have shown that Hpn is an important factor in nickel (and other metals) storage and detoxification. ${ }^{5,6}$ This protein is abundant in the cytoplasm of $H$. pylori and accounts for approximately $2 \%$ of all proteins synthesized by the bacterium (reviewed in ref. 7).

Hpn and Hpn-like are two of over twenty nickel chaperones found in $\mathrm{H}$. pylori. However, the fact that they are biologically important is not the only reason why we decided to study their metal complexes. Hpn, for example, is an amazingly peculiar protein, since 28 out of the 60 amino acids of its sequence

\footnotetext{
${ }^{a}$ Department of Chemical and Pharmaceutical Sciences, University of Ferrara, via Fossato di Mortara, 27, I-44121 Ferrara, Italy.E-mail: rmm@unife.it

${ }^{b}$ Department of Chemistry, University of Wroclaw, F. Joliot-Curie 14, 50-383 Wroclaw, Poland. E-mail: magdalena.rowinska-zyrek@chem.uni.wroc.pl $†$ Electronic supplementary information (ESI) available. See DOI: 10.1039/ c3mt20166j
}

are histidines. ${ }^{8} \mathrm{Hpn}$-like, highly similar in its primary sequence to Hpn, contains some additional polyglutamine repeats.

Polyglutamine sequences are not exceptional in nature, both in "normal" and in pathogenic proteins; it could be very fruitful to disclose the reason for their existence and to learn which thermodynamic and structural properties we can expect from metal complexes containing this type of fragments.

Recently, polyglutamine sequences have been found to play a key role in the so-called polyglutamine diseases, a group of disorders associated with the expansion of the triplet CAG and classified into the group of the trinucleotide repeat-expansion diseases. ${ }^{9}$ Such pathogenic trinucleotide expansions in genes are present in coding regions and are translated into proteins as polyglutamine domains.

All polyglutamine disorders have a strikingly similar course: they are characterized by a progressive degeneration of a group of nervous cells; their major symptoms are quite similar and usually affect people in midlife. Because of the similarities in symptoms, polyQ diseases are hypothesized to have common cellular mechanisms. A conformational change in the expanded glutamine sequences is believed to form the molecular basis for the disease onset, although its exact mechanism is not well understood. What is clear is that the longer the glutamine tract, the higher is the tendency of such proteins to aggregate, mainly in the central nervous system (CNS). Such an aggregation process is definitely associated with neurotoxicity. 
Currently, there are at least 10 known polyQ disorders; among them are Huntington's disease (HD), dentatorubralpallidoluysian atrophy (DRPLA), Machado-Joseph disease (MJD), spinobulbar muscular atrophy (SBMA) and several types of spinocerebellar ataxias. ${ }^{10,11}$ The length of a typical polyglutamine stretch varies from approximately 20 glutamines in normal individuals to over 40 in affected individuals.

Recently, a novel disease model was produced to explain the dependence of the number of CAG repeats (and therefore the number of glutamine repeats) of a genetic mutation with the progression of Huntington's disease and similar trinucleotide repeat disorders with the age of onset and the way the disease will progress in a patient. ${ }^{12}$ It is worth noting that typically, together with the over-expression of Gln residues, an overrepresentation of Pro, Leu and His is also observed. It is also not clear why these specific residues have been co-selected with polyQs during evolution. ${ }^{13}$

Polyglutamine sequences have already been given a reasonable amount of attention in order to understand why such sequences have been evolutionally selected. Michelitsch and Weissman showed that they may act as a 'polar zipper' for protein-protein interactions; ${ }^{14}$ Guo et al. suggested that such a type of interaction might facilitate reversible assembly and disassembly of protein complexes. ${ }^{15}$

In this work, we focus on the impact of such sequences on the structure and thermodynamic stability of metal-peptide complexes in order to shed some light on the bioinorganic chemistry of polyQ repeats. Short N-terminal Hpn and Hpnl fragments (MAHHE- $\mathrm{NH}_{2}$, MAHHEEQ- $\mathrm{NH}_{2}$, MAHHEQQ- $\mathrm{NH}_{2}$ and MAHHEQQHQA-NH $\mathrm{N}_{2}$ ) were chosen for this study in order to obtain precise thermodynamic data on the complexes they form with metal ions. Since these fragments have no defined structure and all side chains of the coordinating residues are available for binding, they seem to be a suitable target to study using our 'protein-fragment' based approach.

\section{Methods}

\section{Peptide synthesis and purification}

Peptides were synthesized according to published methods ${ }^{16}$ by Fmoc/t-butyl chemistry using a Syro XP multiple peptide synthesizer (MultiSynTech GmbH, Witten, Germany). Rink amide MBHA resin (4-(2', $4^{\prime}$-dimethoxyphenyl-Fmoc-aminomethyl)phenoxyacetamido-norleucyl-methylbenzhydrylamine-resin) was used as a solid support for the synthesis of all peptides. The Fmoc protecting group was removed by treatment with $20 \%$ piperidine-DMF. Fmoc-amino acids (4-fold excess) were sequentially coupled with the growing peptide chain using DIPCDI/Oxyma Pure ( $N, N^{\prime}$-diisopropylcarbodiimide-ethyl-2cyano-2-(hydroxyimino)-acetate) (4-fold excess) as an activating mixture for $1 \mathrm{~h}$ at room temperature. Cycles of deprotection of Fmoc and coupling with the subsequent amino acids were repeated until the desired peptide-bound resin was obtained.

Crude peptides were purified by preparative reversed-phase HPLC using a Water Delta Prep 4000 system equipped with a
Jupiter column $\mathrm{C}_{18}(250 \times 30 \mathrm{~mm}, 300 \AA ̊ 丿, 15 \mu \mathrm{m}$ spherical particle size). The column was perfused at a flow rate of

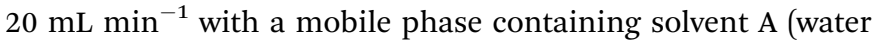
in $0.1 \% \mathrm{TFA}$ ), and a linear gradient from 0 to $15 \%$ of solvent $\mathrm{B}$ $(60 \%, v / v$, acetonitrile in $0.1 \%$ TFA) over $30 \mathrm{~min}$ for the elution of peptides. Analytical HPLC analyses were performed on a Beckman 116 liquid chromatograph equipped with a Beckman 166 diode array detector. Analytical purity of the peptides was determined using a Luna $\mathrm{C}_{18}$ column $(4.6 \times 100 \mathrm{~mm}, 3 \mu \mathrm{m}$ particle size) with the above solvent system (solvents $\mathrm{A}$ and $\mathrm{B}$ ) programmed at a flow rate of $0.5 \mathrm{~mL} \min ^{-1}$ and a linear gradient from $5 \%$ to $100 \%$ B over $25 \mathrm{~min}$. All analogues showed $>90 \%$ purity when monitored at $210 \mathrm{~nm}$. Molecular weights of compounds were determined using a mass spectrometer (ESI Micromass ZMD-2000).

\section{Potentiometric measurements}

Stability constants for proton, $\mathrm{Cu}^{2+}$ and $\mathrm{Ni}^{2+}$ complexes were calculated from two titration curves measured over the $\mathrm{pH}$ range $2-11$ at $25{ }^{\circ} \mathrm{C}$ and ionic strength $0.1 \mathrm{M}(\mathrm{KCl})$ using a total volume of $1.8-2.2 \mathrm{~cm}^{3}$. The $\mathrm{pH}$-metric titrations were performed with a MOLSPIN pH-meter system using a Russel CMAW 711 semi-combined electrode calibrated in proton concentrations using $\mathrm{HCl}^{17}$ Alkali was added with a $0.500 \mathrm{~cm}^{3}$ micrometer syringe, which was calibrated by both weight titration and the titration of standard materials. The purities and the exact concentrations of the ligand solutions were determined by the Gran method. ${ }^{18}$ The ligand concentration was $1.0 \times 10^{-3} \mathrm{M}$, the $\mathrm{Ni}^{2+}$ and the $\mathrm{Cu}^{2+}$-to-ligand ratio was $1: 1.1$.

The HYPERQUAD 2006 and SUPERQUAD programs were used for the stability constant calculations. ${ }^{19,20}$ Standard deviations were given by the program itself and refer to random errors only. The speciation and competition diagrams were computed using the HySS 2006 program. $^{21}$

\section{Spectroscopic studies}

The absorption spectra were recorded on a Cary 300 Bio spectrophotometer. Circular dichroism (CD) spectra were recorded on a Jasco J 715 spectropolarimeter in the 800-230 nm range. Electron paramagnetic resonance (EPR) spectra were recorded on a Bruker ESP 300E spectrometer at X-band frequency $(9.3 \mathrm{GHz})$ in liquid nitrogen. $30 \%$ ethylene glycol was used as a cryoprotectant for EPR measurements.

Solutions were of similar concentration to those used in the potentiometric studies. The UV-Vis, CD and EPR spectroscopic parameters were calculated from the spectra obtained at the $\mathrm{pH}$ values corresponding to the maximum concentration of each particular species, on the basis of distribution diagrams.

\section{Mass spectrometric measurements}

High-resolution mass spectra were obtained on a BrukerQFTMS spectrometer (Bruker Daltonik, Bremen, Germany), equipped with an Apollo II electrospray ionization source with an ion funnel. The mass spectrometer was operated in the negative ion mode. The instrumental parameters were as follows: scan range $m / z$ 400-1600, dry gas-nitrogen, temperature $170{ }^{\circ} \mathrm{C}$, 
ion energy $5 \mathrm{eV}$. Capillary voltage was optimized to the highest $\mathrm{S} / \mathrm{N}$ ratio and it was $4500 \mathrm{~V}$. The small changes of voltage $( \pm 500 \mathrm{~V})$ did not significantly affect the optimized spectra. The samples (metal : ligand in a $1: 1.1$ stoichiometry, [ligand] $]_{\text {tot }}=$ $10^{-4} \mathrm{M}$ ) were prepared in a $1: 1 \mathrm{MeOH}-\mathrm{H}_{2} \mathrm{O}$ mixture at $\mathrm{pH}$ 7.4. The same samples were measured again at $\mathrm{pH} 9$, to prove that stoichiometry does not change with increasing $\mathrm{pH}$. Variation of the solvent composition down to $5 \%$ of $\mathrm{MeOH}$ did not change the species composition. The sample was infused at a flow rate of $3 \mu \mathrm{L} \min ^{-1}$. The instrument was calibrated externally with the Tunemix ${ }^{\mathrm{TM}}$ mixture (Bruker Daltonik, Germany) in quadratic regression mode. Data were processed by using the Bruker Compass DataAnalysis 4.0 program. The mass accuracy for the calibration was better than $5 \mathrm{ppm}$, enabling together with the true isotopic pattern (using SigmaFit) an unambiguous confirmation of the elemental composition of the obtained complex.

\section{Calculation details}

Molecular orbital studies on $\mathrm{Cu}^{2+}$ and $\mathrm{Ni}^{2+}$ cation $1: 1$ complexes with six peptides protected at the C-terminus (the peptides studied experimentally in this work, and two from ref. 35: X-NH $\mathrm{NH}_{2}$, XEQ-NH $\mathrm{NH}_{2}, \mathrm{XEQH}-\mathrm{NH}_{2}, \mathrm{XQ}_{2}-\mathrm{NH}_{2}, \mathrm{XQQHQA-NH}, \mathrm{XQ}_{6} \mathrm{~A}-$ $\mathrm{NH}_{2}$ where $\mathrm{X}=\mathrm{MAHHE}$ ) have been done on the DFT level of theory. All calculations were performed with the Gaussian $09^{22}$ suite of programs using the hybrid functional M05- $2 \mathrm{X}^{23}$ and 6-31G(d,p) basis set. All presented structures show fully DFT optimized structures of the complexes.

\section{Results and discussion}

Structural and thermodynamic properties of $\mathrm{Ni}^{2+}$ and $\mathrm{Cu}^{2+}$ complexes with $\mathrm{N}$-terminal fragments of $\mathrm{Hpn}$ and Hpn-like have been studied and compared to each other by using mass spectrometric, potentiometric, several spectroscopic techniques and theoretical calculations. Full characterization of the complex formation was possible by the correlation of experimental data obtained from various methods and by the outcome of theoretical calculations. Mass spectrometric and potentiometric measurements provided the information on stoichiometry of the formed species; potentiometry also gave the corresponding formation constants necessary to draw the pH-dependent species distribution and competition diagrams; combined UV-Vis, CD and EPR results allowed us to identify the binding sites, the donor atoms and the coordination geometry of complex species formed in solution; computational methods suggested the most plausible three-dimensional complex structure in solution, explaining the impact of Gln residues on the stabilization of the metal complexes.

The presence of the His residue at the 3rd position of the peptide chain suggests that the studied ligands possess a very common and efficient amino-terminal binding site similar to the ATCUN motif in albumin. ${ }^{24}$ Our aim was to obtain detailed thermodynamic and spectroscopic characterization of the metal complexes formed by ligands containing polyQ chains of different lengths, in order to elucidate the impact of the number of glutamine residues on the complexing ability of the corresponding peptides.

\section{Free ligand protonation}

The protonation constants of the studied ligands are collected in Tables 1-4. For each ligand, the highest $\log K$ value can be assigned to the amine group at the N-terminus; the lowest one(s) correspond to the carboxylic side chains of glutamic $\operatorname{acid}(\mathrm{s})$ and the intermediate $\log K$ values arise from the protonation of imidazole side chains of His residues. Neither massspectrometry nor potentiometry allow attributing a single $\log K$ value to a specific residue, when various amino acids of the same type are present in the sequence. NMR measurements could be useful for this purpose, but this was beyond the scope of the present work.

\section{Metal complexes}

ESI-MS experiments showed that all the peptides bind either $\mathrm{Ni}^{2+}$ or $\mathrm{Cu}^{2+}$ ions in equimolar stoichiometry (see Fig. S1, ESI $\dagger$ ). As far as nickel is concerned, negatively charged MS signals corresponding to the species $\left[\mathrm{NiLH}_{-x}\right]^{2-}$ for MAHHEQQHQA$\mathrm{NH}_{2}$, MAHHEQQ-NH ${ }_{2}$ and MAHHEEQ-NH ${ }_{2}(\mathrm{~m} / \mathrm{z}=634.2,466.1$ and 466.6, respectively), and $\left[\mathrm{NiLH}_{-2}\right]^{-}$for MAHHE-NH $\mathrm{NH}_{2}(\mathrm{~m} / z=$ 677.2) were detected, along with some sodium and chloride adducts. As for copper ions, exactly the same species were found, corresponding to the signals at $m / z=636.7,468.6$, 469.1 and 682.2, respectively. The signal attribution was confirmed by means of the analysis of the isotopic pattern and the comparison of the experimental clusters with their simulations.

Thermodynamic and spectroscopic results concerning complex-formation equilibria of the ligands under study and $\mathrm{Ni}^{2+}$ or $\mathrm{Cu}^{2+}$ ions are reported in Tables 1-4. The corresponding distribution diagrams, based on a series of potentiometric titrations, are reported in the ESI $\dagger$ (Fig. S2).

\section{$\mathrm{Ni}^{2+}$ complexes}

The whole of the potentiometric and spectroscopic investigation confirmed that in all the nickel complexes the binding mode is albumin-like: $\left\{\mathrm{NH}_{2}, 2 \mathrm{~N}^{-}, \mathrm{N}_{\mathrm{Im}}\right\}$ or, shortly, $4 \mathrm{~N}$. The metal ion is bound to the imidazole of His-3, to the N-terminal amine nitrogen and to two amide nitrogens situated between the N-terminus and His-3 in a square-planar geometry. For clarity, and because of the lack of significant differences in the coordination modes, all four ligands will be discussed together.

The formation of nickel complexes starts at pH 5 for all the ligands and the metal coordination mode is already albuminlike. At that $\mathrm{pH}$ value, the carboxylate side chains of Glu residues are already deprotonated, while additional His residues are still protonated. The coordination modes, evidenced by the typical CD spectra (ESI, $\uparrow$ Fig. S3), are all very similar. The same conclusion is also suggested by the UV-Vis wavelength of maximum absorption at $419 \mathrm{~nm}^{25}$ (see Tables 1-4 and Fig. S4, ESI $\dagger$ ). Above neutral $\mathrm{pH}$, the spectrophotometric parameters do not depend on the $\mathrm{pH}$ value, implying no change in the coordination mode when $\mathrm{pH}$ is increased. In the alkaline $\mathrm{pH}$ range, the $\mathrm{p} K$ value of the last deprotonation step and the 
Table 1 Potentiometric and spectroscopic data for proton, $\mathrm{Cu}^{2+}$ and $\mathrm{Ni}^{2+}$ complexes of the MAHHE- $\mathrm{NH}_{2}$ peptide, at $25^{\circ} \mathrm{C}$ and $I=0.1 \mathrm{M}(\mathrm{KCl})$. Log $K$ values refer to the last ligand (or complex) protonation step. Uncertainty in the last significant figure is reported in parentheses

\begin{tabular}{|c|c|c|c|c|c|c|c|c|c|}
\hline Species & $\log \beta$ & $\log K$ & \multicolumn{2}{|l|}{ UV-Vis } & \multicolumn{2}{|l|}{$\mathrm{CD}$} & \multicolumn{2}{|l|}{ EPR } & $\mathrm{pH}$ \\
\hline $\mathrm{HL}$ & $7.73(6)$ & 7.73 & & & & & & & \\
\hline $\mathrm{H}_{3} \mathrm{~L}^{2+}$ & $20.31(5)$ & 6.07 & & & & & & & \\
\hline $\mathrm{H}_{4} \mathrm{~L}^{3+}$ & $24.43(5)$ & 4.12 & & & & & & & \\
\hline$[\mathrm{CuL}]^{+}$ & $10.96(4)$ & 4.73 & 525 & 67 & 565 & -0.25 & 124 & 2.22 & 4.5 \\
\hline \multirow[t]{4}{*}[\mathrm{CuH}_{-1}\mathrm{L}]{} & $6.23(2)$ & 6.47 & 526 & 112 & 565 & -0.43 & 202 & 2.18 & 6.0 \\
\hline & & & & & 489 & 0.37 & & & \\
\hline & & & & & 309 & 0.98 & & & \\
\hline & & & & & 271 & -1.98 & & & \\
\hline \multirow[t]{2}{*}[\mathrm{CuH}_{-2}\mathrm{L}]{$^{-}$} & $-0.24(2)$ & 9.16 & 528 & 143 & 568 & -0.43 & 199 & 2.18 & 8.0 \\
\hline & & & & & 490 & 0.41 & & & \\
\hline & & & & & 275 & -1.97 & & & \\
\hline \multirow[t]{3}{*}[\mathrm{NiL}]{$^{+}$} & $6.16(9)$ & 5.37 & 415 & 30 & 476 & -0.69 & - & - & 6.0 \\
\hline & & & & & 411 & 0.53 & & & \\
\hline & & & & & 260 & 1.18 & & & \\
\hline \multirow[t]{3}{*}[\mathrm{NiH}_{-1}\mathrm{L}]{} & $0.79(2)$ & 8.16 & 423 & 94 & 476 & -1.70 & & & 7.0 \\
\hline & & & & & 410 & 1.30 & & & \\
\hline & & & & & 260 & 2.49 & & & \\
\hline \multirow[t]{3}{*}[\mathrm{NiH}_{-2}\mathrm{L}]{$^{-}$} & $-7.37(6)$ & & 422 & 95 & 476 & -1.77 & - & - & 10.0 \\
\hline & & & & & 411 & 1.33 & & & \\
\hline & & & & & 259 & 2.51 & & & \\
\hline
\end{tabular}

Table 2 Potentiometric and spectroscopic data for proton, $\mathrm{Cu}^{2+}$ and $\mathrm{Ni}^{2+}$ complexes of the MAHHEEQ- $\mathrm{NH}_{2}$ peptide, at $25^{\circ} \mathrm{C}$ and $I=0.1 \mathrm{M}(\mathrm{KCl})$. Log $\mathrm{K}$ values refer to the last ligand (or complex) protonation step. Uncertainty in the last significant figure is reported in parentheses

\begin{tabular}{|c|c|c|c|c|c|c|c|c|c|}
\hline Species & $\log \beta$ & $\log K$ & \multicolumn{2}{|l|}{ UV-Vis } & \multicolumn{2}{|l|}{$\mathrm{CD}$} & \multicolumn{2}{|l|}{$\underline{\text { EPR }}$} & $\mathrm{pH}$ \\
\hline $\mathrm{HL}^{-}$ & 7.69(1) & 7.69 & & & & & & & \\
\hline $\mathrm{H}_{3} \mathrm{~L}^{+}$ & $20.42(1)$ & 6.01 & & & & & & & \\
\hline $\mathrm{H}_{4} \mathrm{~L}^{2+}$ & 24.78(1) & 4.36 & & & & & & & \\
\hline $\mathrm{H}_{5} \mathrm{~L}^{3+}$ & 28.21(1) & 3.43 & & & & & & & \\
\hline [CuL] & & & & & 272 & -0.57 & & & \\
\hline \multirow{4}{*}[\mathrm{CuH}_{-1}\mathrm{L}]{$^{-}$} & $6.02(2)$ & 6.23 & 524 & 56 & 564 & -0.31 & 202 & 2.17 & 5.5 \\
\hline & & & & & 489 & 0.28 & & & \\
\hline & & & & & 308 & 0.81 & & & \\
\hline & & & & & 270 & -1.32 & & & \\
\hline$\left[\mathrm{CuH}_{-2} \mathrm{~L}\right]^{2-}$ & $-0.21(5)$ & 8.60 & 527 & 67 & 563 & -0.34 & 199 & 2.18 & 7.5 \\
\hline & \multirow{2}{*}{$-8.81(6)$} & & & & 309 & 0.96 & & & \\
\hline & & & & & 274 & -1.69 & & & \\
\hline \multirow[t]{3}{*}[\mathrm{NiH}_{-1}\mathrm{L}]{$^{-}$} & \multirow[t]{3}{*}{$0.86(1)$} & \multirow[t]{3}{*}{7.46} & 418 & 29 & 477 & -1.07 & - & - & 6.5 \\
\hline & & & & & 410 & 0.84 & & & \\
\hline & & & & & 259 & 1.55 & & & \\
\hline \multirow[t]{3}{*}[\mathrm{NiH}_{-2}\mathrm{L}]{$^{2-}$} & \multirow[t]{3}{*}{$-6.60(7)$} & & 423 & 115 & 477 & -1.72 & - & - & 10.0 \\
\hline & & & & & 411 & 1.32 & & & \\
\hline & & & & & 260 & 2.43 & & & \\
\hline
\end{tabular}


Table 3 Potentiometric and spectroscopic data for proton, $\mathrm{Cu}^{2+}$ and $\mathrm{Ni}^{2+}$ complexes of the MAHHEQQ- $\mathrm{NH}_{2}$ peptide, at $25^{\circ} \mathrm{C}$ and $I=0.1 \mathrm{M}(\mathrm{KCl})$. $\mathrm{Log} K$ values refer to the last ligand (or complex) protonation step. Uncertainty in the last significant figure is reported in parentheses

\begin{tabular}{|c|c|c|c|c|c|c|c|c|c|}
\hline Species & $\log \beta$ & $\log K$ & \multicolumn{2}{|l|}{ UV-Vis } & \multicolumn{2}{|l|}{$\mathrm{CD}$} & \multicolumn{2}{|l|}{ EPR } & $\mathrm{pH}$ \\
\hline HL & $7.68(3)$ & 7.68 & & & & & & & \\
\hline $\mathrm{H}_{3} \mathrm{~L}^{2+}$ & $20.22(3)$ & 6.01 & & & & & & & \\
\hline $\mathrm{H}_{4} \mathrm{~L}^{3+}$ & $24.15(4)$ & 3.93 & & & & & & & \\
\hline$[\mathrm{CuL}]^{+}$ & $10.39(6)$ & 4.75 & 531 & 59 & 565 & -0.22 & 129 & 2.21 & 4.5 \\
\hline \multirow[t]{4}{*}[\mathrm{CuH}_{-1}\mathrm{L}]{} & $5.64(9)$ & 4.76 & 525 & 107 & 565 & -0.42 & 204 & 2.18 & 5 \\
\hline & & & & & 487 & 0.42 & & & \\
\hline & & & & & 308 & 1.02 & & & \\
\hline & & & & & 273 & -1.98 & & & \\
\hline \multirow[t]{2}{*}[\mathrm{CuH}_{-2}\mathrm{L}]{$^{-}$} & \multirow[t]{2}{*}{$0.88(7)$} & 8.72 & 528 & 119 & 567 & -0.41 & 201 & 2.18 & 7 \\
\hline & & & & & 488 & 0.49 & & & \\
\hline & $-7.84(7)$ & & & & 273 & -2.03 & & & \\
\hline \multirow[t]{3}{*}[\mathrm{NiH}_{-1}\mathrm{L}]{} & \multirow[t]{3}{*}{$1.09(1)$} & \multirow[t]{3}{*}{6.85} & 423 & 25 & 477 & -1.51 & - & - & 6 \\
\hline & & & & & 411 & 1.18 & & & \\
\hline & & & & & 258 & 2.04 & & & \\
\hline \multirow[t]{3}{*}[\mathrm{NiH}_{-2}\mathrm{L}]{$^{-}$} & \multirow[t]{3}{*}{$-5.76(3)$} & & 419 & 102 & 476 & -2.04 & - & - & 9 \\
\hline & & & & & 411 & 1.67 & & & \\
\hline & & & & & 261 & 2.47 & & & \\
\hline
\end{tabular}

Table 4 Potentiometric and spectroscopic data for proton, $\mathrm{Cu}^{2+}$ and $\mathrm{Ni}^{2+}$ complexes of the MAHHEQQHQA-NH 2 peptide, at $25^{\circ} \mathrm{C}$ and $I=0.1 \mathrm{M}(\mathrm{KCl})$. Log $K$ values refer to the last ligand (or complex) protonation step. Uncertainty in the last significant figure is reported in parentheses

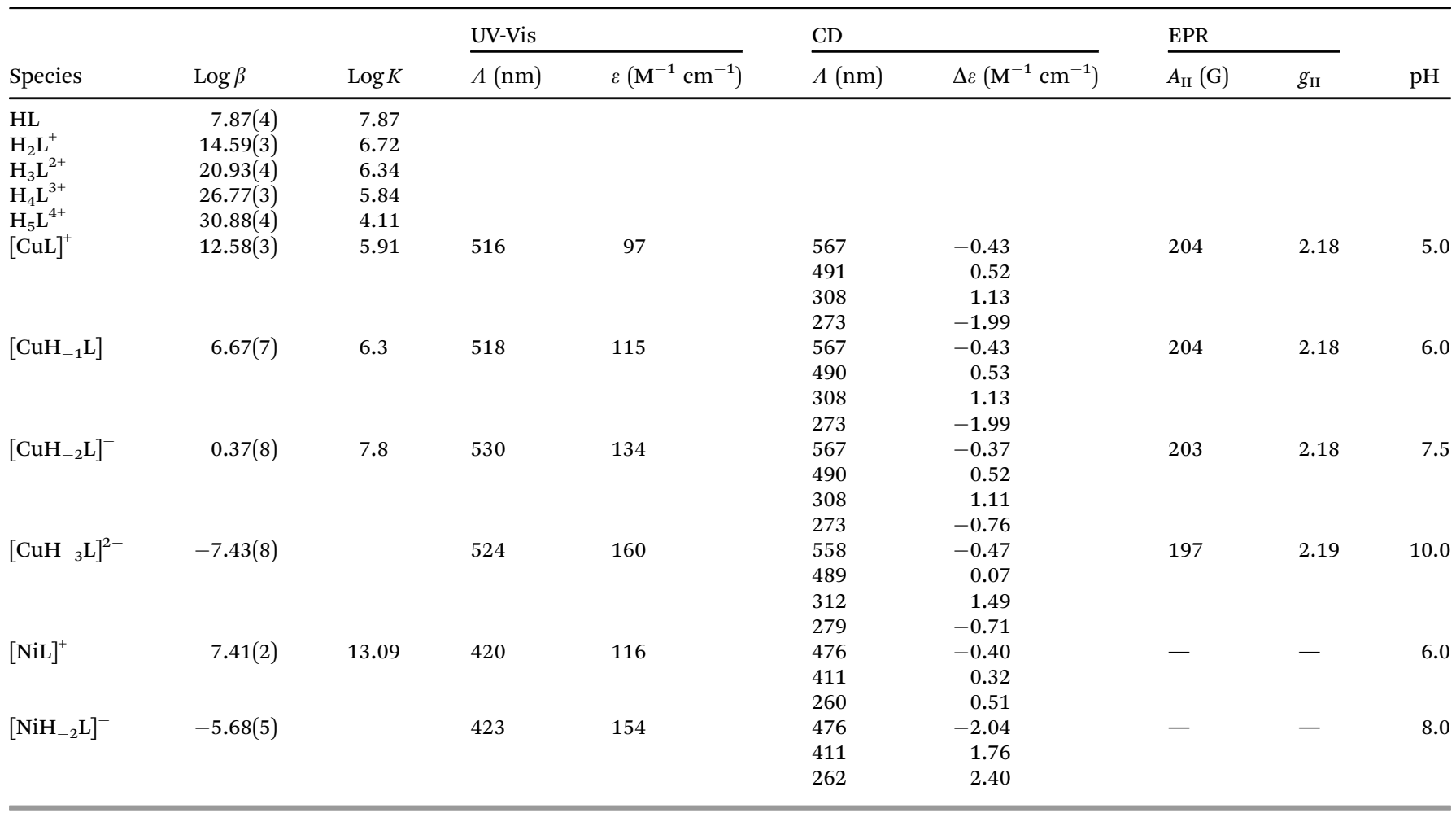

absence of any significant shifts in CD and UV-Vis spectra suggest the deprotonation of the unbound histidine, without its involvement in coordination (in the case of MAHHEQQHQA- $\mathrm{NH}_{2}$, containing an extra His residue in the sequence, the simultaneous deprotonation of the two unbound His residues is observed). 


\section{$\mathrm{Cu}^{2+}$ complexes}

The copper ion starts to bind the four peptides at $\mathrm{pH}$ lower than 4 , where carboxylate side-chains of Glu residues are only partially deprotonated and protonated complexes are likely to form. According to CD and UV-Vis spectra (d-d band at $524 \mathrm{~nm}$ ), EPR parameters $\left(A_{\|}=205 \mathrm{G}\right.$ and $\left.g_{\|}=2.18\right)$ and formationconstant values, the copper ion is already surrounded by four nitrogen atoms at $\mathrm{pH} \mathrm{5.}{ }^{26,27}$ As in the case of nickel, the most likely geometry is square-planar with the typical albumin-like coordination mode.

There are no significant spectroscopic differences among the copper complexes formed in the whole $\mathrm{pH}$ range. Once again, the deprotonations of unbound histidines, which do not affect the coordination mode, can be observed in the alkaline $\mathrm{pH}$ range. The last deprotonation step detected in every system could be attributed to the deprotonation of either the pyrrolic nitrogen atom of the imidazole ring already bound to copper or an axial water molecule.

\section{Molecular modeling}

Theoretical calculations are in excellent agreement with experimental results: all of the studied complexes can form stable albumin-like complexes with copper and nickel ions (Fig. 1).

In all theoretically calculated complexes, one can find a typical square-planar binding motif: the metal ions are bound to the imidazole nitrogen of His-3, two amide nitrogens and an amine nitrogen from the N-terminus. The impact of glutamines on the stability of the complexes can be explained via indirect ligandcation interactions - glutamine side chains are not directly involved in the metal-peptide binding, but OCNH groups from the peptide backbone and Gln side chains form an extensive hydrogen-bond (HB) network that locks the metal ion inside.

HBs are the key to understand the structure and properties not only of molecular complexes ${ }^{28,29}$ (intermolecular HBs) but also of the secondary structure of peptides and proteins (intramolecular $\mathrm{HBs}) .^{30-32}$ In helices and B-sheets, formamide-like (OCNH) fragments of the peptide backbone create cooperative $\mathrm{HB}$ chains. Theoretical research on similar hydrogen bonds in the chains of formamides describes such bonds as very cooperative: interaction enthalpy increases rapidly with the number of hydrogen bonds. ${ }^{33}$ Glutamine side chains, having the same (OCNH) fragments, follow the same pattern. ${ }^{34}$

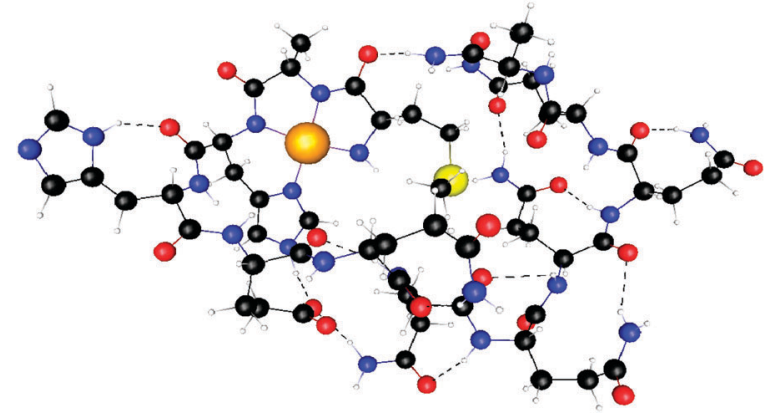

Fig. 1 The common metal-peptide binding pattern. The CU-MAHHEQQQQQQ-NH complex is reported as an example; the metal ion is in orange.
In the metal-peptide complexes presented here, the Q-side chains and backbone OCNH groups form rich $\mathrm{HB}$ networks (involving up to $5 \mathrm{OCNH}$ fragments in one chain) that shape the complex. In all studied $\mathrm{Cu}^{2+}$ and $\mathrm{Ni}^{2+} 1: 1$ complexes (with the peptides from this work and two additional ones from ref. 35: MAHHEEQHG- $\mathrm{NH}_{2}$ and MAHHEQQQQQQA- $\mathrm{NH}_{2}$ ), Q residues do not play any direct role in the metal-peptide complexformation; however, a set of HBs around the metal-binding space locks the metal "inside" the peptide (Fig. 2). Such peptide folding increases the stability of the complex. The number of intramolecular hydrogen bonds directly depends on the number of $\mathrm{Q}$ side chains: in the shortest peptide $\left(\mathrm{MAHHE}-\mathrm{NH}_{2}\right)$, one can find
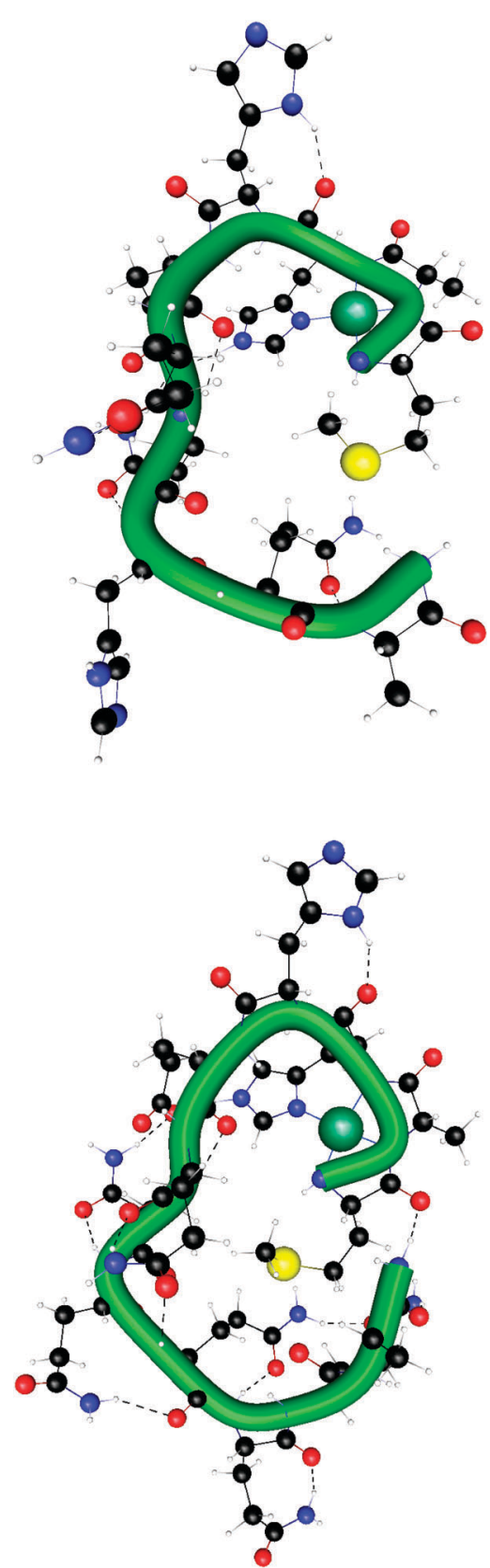

Fig. 2 Ni-MAHHEEQQHG-NH ${ }_{2}$ (up) and Ni-MAHHEQQQQQQA-NH ${ }_{2}$ (down). Network of $\mathrm{H}$-bonds. Green tubes follow backbones. 
only three H-bonds, whereas in the case of the $\mathrm{Q}$ rich MAHHEQQQQQQA- $\mathrm{NH}_{2}$ ligand, 15 HBs create an extensive network that closes the metal cation inside of a spring-trap like structure. Fully optimized structures of all complexes with $\mathrm{Cu}^{2+}$ and $\mathrm{Ni}^{2+}$ are given in the ESI $\dagger$ (Fig. S5). In the case of the other complexes, the number of HBs lies between these numbers, again corresponding to the number of $\mathrm{Q}$ residues in the peptide (e.g. all complexes with $2 \mathrm{Q}$ or $3 \mathrm{Q}$ residues, Ni-MAHHEQQ$\mathrm{NH}_{2}, \mathrm{Cu}-\mathrm{MAHHEQQ- \textrm {NH } _ { 2 }}$, Ni-MAHHEQQHQA-NH$H_{2}$ and $\mathrm{Cu}-$ MAHHEQQHQA- $\mathrm{NH}_{2}$, have 6 or $7 \mathrm{H}$-bonds).

In the investigated complexes, all Q side chains are involved in HB interactions. Their flexible nature (differently from the more rigid OCNH bearing the peptide backbone) is responsible for creating chains of HBs, where cooperativity provides non-addictive effects to interaction enthalpy. Under certain circumstances, the strongest hydrogen bond in the formamide chain has close to $250 \%$ of interaction enthalpy of the formamide dimer. ${ }^{33}$

The extended number of $\mathrm{Q}$ residues supports peptide folding around the metal cation and creates $\mathrm{H}$-bonds organized in chains. Such topology causes non-linear contribution to interaction enthalpies of the H-bonds that leads to a non-linear increase in stability of the Q-rich complexes.

\section{Impact of Qs on complex stability}

The experimental results described in the previous section confirm the typical albumin-like binding for both of the studied metals. Since the coordination mode is the same for all of the species, the only differences in thermodynamic stability are the result of the influence of the neighboring peptide sequence containing amino acid residues not directly involved in complexation.

The N-terminal domain of the peptides studied here, i.e. the sequence which takes part in metal ion coordination, is the same for each ligand ( $\mathrm{MAH}-)$. In contrast, the C-terminal sequences are different, the main alteration being the amount of glutamine residues $\left(-\mathrm{HE}-\mathrm{NH}_{2},-\mathrm{HEEQ}-\mathrm{NH}_{2},-\mathrm{HEQQ}-\mathrm{NH}_{2}\right.$, and -HEQQHQA- $\mathrm{NH}_{2}$ ). The easiest way to compare the binding ability of all of the studied ligands is to build up a competition plot, referring to a hypothetical situation, where all the ligands are present at the same time and "compete" to bind the metal ion. Such a plot can be calculated by means of the speciation models obtained by potentiometry and assuming that no mixedligand species is formed. This assumption looks likely in the present case, since each ligand is able to saturate the coordination positions of the metal ion. Fig. 3 and 4 show the competition among the ligands described in this paper. The plots are based on stability constants and are made using the HySS program, ${ }^{21}$ like the distribution plots (Fig. S2, ESI $\dagger$ ) are; the difference is, that in this case, based on the constants for all complexes with the same metal, a simulation is made for the metal and all of the ligands together, at equal concentrations. Then, the differently protonated species from the same complex are summed up and presented in the form of a plot, which shows which ligand is most efficient in binding the discussed metal ion.

The dependence of the complex stability on the number of glutamine residues is quite striking, in the alkaline $\mathrm{pH}$ range.

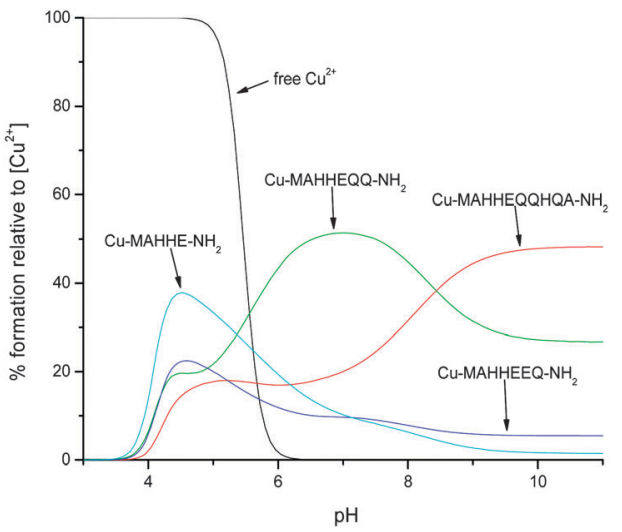

Fig. 3 The distribution of $\mathrm{Cu}^{2+}$ among MAHHE- $\mathrm{NH}_{2}$, MAHHEEQ-NH 2 , MAHHEQQ$\mathrm{NH}_{2}$, and MAHHEQQHQA-NH$H_{2}$ ligands $(\mathrm{L})$, in aqueous solution. $[\mathrm{L}]=\left[\mathrm{Cu}^{2+}\right]_{\text {tot }}=$ $0.001 \mathrm{M}$.

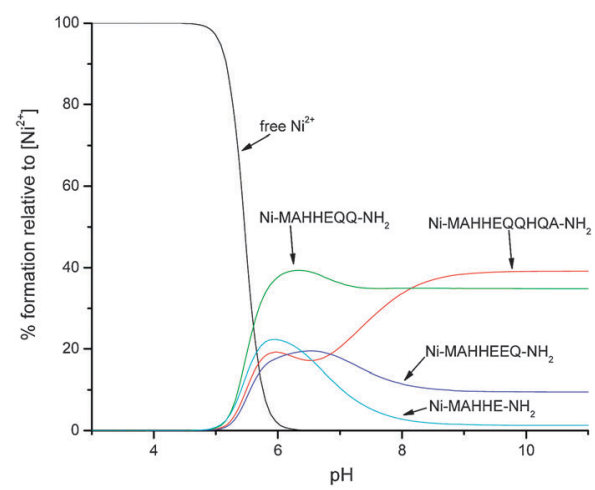

Fig. 4 The distribution of $\mathrm{Ni}^{2+}$ among MAHHE- $\mathrm{NH}_{2}$, MAHHEEQ-NH 2 , MAHHEQQ$\mathrm{NH}_{2}$, and MAHHEQQHQA-NH${ }_{2}$ ligands $(\mathrm{L})$, in aqueous solution. $[\mathrm{L}]=\left[\mathrm{Ni}^{2+}\right]_{\text {tot }}=$ $0.001 \mathrm{M}$.

It is worth noting that MAHHEEQ- $\mathrm{NH}_{2}$ contains an additional glutamic acid, while a further histidine is present in the peptide MAHHEQQHQA-NH $\mathrm{N}_{2}$; although not bound to the metal ion, these residues can also affect the stability of the complex, in their protonation-deprotonation $\mathrm{pH}$ range (4-7), e.g. for effects depending on the ligand charge. However, above $\mathrm{pH} 8$, no further deprotonation of unbound side-chains is possible and the coordination mode of the complex does not change: the only thing that can affect the complex stability is the presence of a different number of glutamine residues, or, to be more exact, the presence of numerous cooperative hydrogen bonds these residues are able to form. The change of structure caused by the formation of such a stabilizing HB network may additionally form a kind of cage around the central metal ion, protecting it from hydrolysis.

\section{Conclusions}

The peptide-model approach ${ }^{36}$ used for investigating metalprotein interactions normally makes use of fragments mostly containing the metal-binding residues. Using this method, our research group recently discovered several interesting facts 
about coordination modes of Hpn fragments. ${ }^{7,37,38}$ The results reported in the present paper suggest that this approach is not fully appropriate if further amino acid residues, which do not directly take part in coordination, can affect the thermodynamic stability of metal complexes. In this work, the polyQ long-range stabilizing effect was proved by means of both many different experimental techniques and theoretical calculations. These findings not only shed some light on the coordination chemistry of $H$. pylori's nickel chaperones, but also encourage reconsidering the molecular basis of polyglutamine diseases.

\section{Acknowledgements}

This work was supported by the Polish Ministry of Science and Higher Education (KBN N N204 146537) and by the University of Ferrara (FAR 2011). M. Rowinska-Zyrek is supported by a scholarship from the Foundation for Polish Science.

\section{Notes and references}

1 P. Bauerfeind, R. Garner, B. Dunn and H. Mobley, Gut, 1997, 40, 25.

2 J. Olson and J. Maier, Science, 2002, 298, 1788.

3 J. Parsonnet, S. Hansen, L. Rodriguez, A. B. Gelb, R. A. Warnke, E. Jellum, N. Orentreich, J. H. Vogelman and G. D. Friedman, N. Engl. J. Med., 1994, 330, 1267.

4 J. G. Kusters, A. H. M. van Vliet and E. J. Kuipers, Clin. Microbiol. Rev., 2006, 19(3), 449.

5 Y. Li and D. B. Zamble, Chem. Rev., 2009, 109, 4617.

6 S. Seshadri, S. L. Benoit and R. J. Maier, J. Bacteriol., 2007, 189, 4120.

7 D. Witkowska, M. Rowińska-Żyrek, G. Valensin and H. Kozłowski, Coord. Chem. Rev., 2012, 256, 133.

8 J. V. Gilbert, J. Ramakrishna, F. W. Sunderman, A. Wright Jr. and A. G. Plaut, Am. Soc. Microbiol., 1995, 63, 2682.

9 H. T. Orr and H. Y. Zoghbi, Annu. Rev. Neurosci., 2007, 30, 575 .

10 E. L. Altschuler, N. V. Hud, J. A. Mazrimas and B. Rupp, J. Pept. Res., 1997, 50, 73.

11 S. L. Hands and A. Wyttenbach, Acta Neuropathol., 2010, 120, 419.

12 S. Kaplan, S. Itzkovitz and E. Shapiro, PLoS Comput. Biol., 2007, 3(11), 235.

13 M. Ramazzotti, E. Monsellier, C. Kamoun, D. Degl'Innocenti and R. Melki, PLoS One, 2012, 7(2), e30824.

14 M. Michelitsch and J. S. Weissman, Proc. Natl. Acad. Sci. U. S. A., 2000, 97, 11910.

15 L. Guo, A. Han, D. L. Bates, J. Cao and L. Chen, Proc. Natl. Acad. Sci. U. S. A., 2007, 104, 4297.

16 N. L. Benoiton, Chemistry of Peptide Synthesis, Taylor \& Francis, London, 2005, pp. 125-154.

17 H. Irving, M. Miles and L. Pettit, Anal. Chim. Acta, 1967, 38, 475.

18 G. Gran, Acta Chem. Scand., 1950, 4, 559.
19 P. Gans, A. Sabatini and A. Vacca, J. Chem. Soc., Dalton Trans., 1985, 1195.

20 P. Gans, A. Sabatini and A. Vacca, Talanta, 1996, 43, 1739.

21 L. Alderighi, P. Gans, A. Ienco, D. Peters, A. Sabatini and A. Vacca, Coord. Chem. Rev., 1999, 184, 311.

22 M. J. Frisch, G. W. Trucks, H. B. Schlegel, G. E. Scuseria, M. A. Robb, J. R. Cheeseman, G. Scalmani, V. Barone, B. Mennucci, G. A. Petersson, H. Nakatsuji, M. Caricato, X. Li, H. P. Hratchian, A. F. Izmaylov, J. Bloino, G. Zheng, J. L. Sonnenberg, M. Hada, M. Ehara, K. Toyota, R. Fukuda, J. Hasegawa, M. Ishida, T. Nakajima, Y. Honda, O. Kitao, H. Nakai, T. Vreven, J. A. Montgomery, Jr., J. E. Peralta, F. Ogliaro, M. Bearpark, J. J. Heyd, E. Brothers, K. N. Kudin, V. N. Staroverov, R. Kobayashi, J. Normand, K. Raghavachari, A. Rendell, J. C. Burant, S. S. Iyengar, J. Tomasi, M. Cossi, N. Rega, J. M. Millam, M. Klene, J. E. Knox, J. B. Cross, V. Bakken, C. Adamo, J. Jaramillo, R. Gomperts, R. E. Stratmann, O. Yazyev, A. J. Austin, R. Cammi, C. Pomelli, J. W. Ochterski, R. L. Martin, K. Morokuma, V. G. Zakrzewski, G. A. Voth, P. Salvador, J. J. Dannenberg, S. Dapprich, A. D. Daniels, Ö. Farkas, J. B. Foresman, J. V. Ortiz, J. Cioslowski and D. J. Fox, Gaussian 09, Revision C.01, Gaussian, Inc., Wallingford, CT, 2009.

23 Y. Zhao, N. E. Schultz and D. G. Truhlar, J. Chem. Theory Comput., 2006, 2, 364.

24 H. Kozłowski, T. Kowalik-Jankowska and M. Jeżowska-Bojczuk, Coord. Chem., 2005, 249, 2323.

25 S. A. Ross and C. J. Burrows, Inorg. Chem., 1998, 37, 5358.

26 P. Mlynarz, N. Gaggelli, J. Panek, M. Stasiak, G. Valensin,

T. Kowalik-Jankowska, M. L. Leplawy, Z. Latajka and H. Kozlowski, J. Chem. Soc., Dalton Trans., 2000, 1033.

27 L. D. Pettit, J. E. Gregor and H. Kozlowski, in Perspectives on Bioinorganic Chemistry, ed. R. W. Hay, J. R. Dilworth and K. B. Nolan, JAI Press, London, 1991, vol. 1, pp. 1-41.

28 Z. Mielke and Z. Latajka, J. Phys. Chem., 2000, 104, 3764.

29 M. Wierzejewska and R. Wieczorek, Chem. Phys., 2003, 287, 169.

30 R. Wieczorek and J. J. Dannenberg, J. Am. Chem. Soc., 2003, 125, 8124.

31 R. Wieczorek and J. J. Dannenberg, J. Am. Chem. Soc., 2004, 126, 14198.

32 P. Salvador, R. Wieczorek and J. J. Dannenberg, J. Phys. Chem. B, 2007, 111, 2398.

33 N. Kobko and J. J. Dannenberg, J. Phys. Chem. B, 2003, 107, 10389.

34 J. A. Plumley and J. J. Dannenberg, J. Am. Chem. Soc., 2010, 132, 1758.

35 D. Witkowska, S. Bielinska, W. Kamysz and H. Kozlowski, J. Inorg. Biochem., 2011, 105, 208.

36 H. Kozlowski, M. Luczkowski and M. Remelli, Dalton Trans., 2010, 39, 6371.

37 M. Rowińska-Żyrek, D. Witkowska, S. Bielinska, W. Kamysz and H. Kozlowski, Dalton Trans., 2011, 40, 5604-5610.

38 D. Witkowska, R. Politano, M. Rowińska-Żyrek, R. Guerrini, M. Remelli and H. Kozlowski, Chem.-Eur. J., 2012, 18(35), 11088. 